\title{
Ocorrência do gene da toxina da síndrome do choque tóxico em Staphylococcus spp. isolados de leite de vacas com mastite e de leite cru refrigerado*
}

\section{Occurrence of the toxic shock syndrome toxin gene in Staphylococcus spp. isolated from bovine mastitis milk and refrigerated raw milk}

\author{
Fabíola Fonseca Ângelo, ${ }^{* *}$ Edna Froeder Arcuri, ${ }^{* * *}$ Nélio José de Andrade ${ }^{* * * *}$
}

\begin{abstract}
Resumo
Avaliou-se a presença do gene (tst-1) para Toxina da Síndrome do Choque Tóxico-1 (TSST-1), utilizando-se a técnica de Reação em Cadeia da Polimerase (PCR) em um total de 264 Staphylococcus spp. isolados de leite. Desses, 221 eram Staphylococcus aureus, 33 Staphylococcus coagulase negativo (SCN) e 10 Staphylococcus coagulase positivo (SCP). As amostras eram oriundas de vacas com mastite $(n=96)$ e de leite cru refrigerado $(n=168)$, coletadas de 46 e 22 propriedades, respectivamente. As amostras foram coletadas de rebanhos localizados em diferentes regiões dos Estados de Minas Gerais e Rio de Janeiro. Observou-se produto de amplificação (250 pares de base-pb) na reação de PCR para tst-1 em sete amostras $(2,6 \%)$, sendo todas as estirpes identificadas como Staphylococcus aureus isoladas de leite cru refrigerado. Embora a detecção do gene não indique a produção da toxina, o monitoramento de estirpes bacterianas potencialmente produtoras torna-se importante como forma de realizar um levantamento epidemiológico e controle dos rebanhos leiteiros brasileiros, uma vez que esse gene está associado aos elementos genéticos móveis, representando um risco à possível transferência horizontal de genes para outras bactérias. Além disso, a presença desses genes tem sido associada à presença de genes para enterotoxinas estafilocócicas, o que pode implicar o aumento da patogenicidade dos isolados bacterianos e um potencial risco à saúde pública.
\end{abstract}

Palavras-chave: Staphylococcus spp., síndrome do choque tóxico, tst-1, PCR.

\begin{abstract}
Was evaluated the presence of the gene (tst -1) for toxic shock syndrome toxin - 1 (TSST -1), using the technique of Polymerase Chain Reaction (PCR) on a total of 264 Staphylococcus spp. isolated from milk. Of these, 221 were Staphylococcus aureus, 33 Staphylococcus coagulase negative (SCN) and 10 Staphylococcus coagulase positive (SCP). The samples were from cows with mastitis $(n=96)$ and refrigerated raw milk $(n=168)$, collected from 46 and 22 dairy herds, respectively. Samples were collected from herds located in different regions of Minas Gerais and Rio de Janeiro States. Was observed PCR amplification of the tst-1 gene (250 base pairs-bp) in seven (2.6\%) samples, and all strains of Staphylococcus aureus isolated from refrigerated raw milk. Although its detection in isolated does not mean that it will be expressed, monitoring of bacterial strains producing potentially becomes important as performing an epidemiological survey and control of Brazilian dairy herds, since this gene is associated with mobile genetic elements, representing a risk to possible horizontal gene transfer to other bacteria. Furthermore, the presence of these genes have been associated with the presence of genes for enterotoxins, which may result in increased pathogenicity of the isolates and a potential risk to public health.
\end{abstract}

Keywords: Staphylococcus spp., toxic shock syndrome, tst-1, PCR.

\section{Introdução}

Staphylococcus spp. é um micro-organismo potencialmente produtor de uma variedade de fatores de virulência que contribuem para sua patogenicidade e persistência. Dentre esses fatores, destaca-se Toxina da Síndrome do Choque Tóxico (TSST-1), uma proteína altamente resistente às proteases e desnaturação térmica. Codificada pelo gene tst-1, a TSST-1 de Staphylococcus tem sido reconhecida como a principal causa da síndrome do choque tóxico, caracterizada por febre, hipotensão e morte em humanos (Zschock et al., 2000; Dinges et al., 2000; Stiles et al., 2005; Hale et al., 2006). Embora os principais trabalhos demonstrem a presença de tst-1 em isolados humanos (Tsen et al., 1998; Deurenberg et al., 2005), a presença desse gene vem sendo verificada também em isolados animais e diversos alimentos, incluindo isolados de leite de vacas com mastite, leite cru e carnes e derivados (Jones e Wieneke, 1986; Zschock et al., 2005; Wang et al., 2009; Gunaydin et al., 2011).

*Recebido em 26 de novembro de 2013 e aceito em 26 de junho de 2014.

**Professora Adjunta I Universidade Federal da Paraíba, João Pessoa, PB-Brasil. Distrito Industrial de Mangabeira, Via Local, s/n. Quadra 252, Lote 501 58055-000-João Pessoa, PB-Brasil.

*** Pesquisadora Embrapa Gado de Leite, Juiz de Fora, MG-Brasil.

****Professor Titular Universidade Federal de Viçosa, Viçosa, MG-Brasil.

Autor para correspondência: fabiolangelo@yahoo.com.br 
O tst-1 está associado com elementos genéticos móveis, como profagos, ilhas de patogenicidade de $S$. aureus e plasmídeo, acarretando em possível transferência do gene para outras bactérias. Além disso, tem sido verificada associação da presença de genes para a toxina da síndrome choque tóxico e a presença de genes para as enterotoxinas estafilocócicas que pode implicar no aumento da patogenicidade dos isolados bacterianos e um potencial risco à saúde pública (FUEYO et al., 2005; FARAHMAND et al., 2013).

Devido à importância de espécies de Staphylococcus que apresentem tst-1 no leite e o potencial risco à saúde pública, este trabalho se propôs a detectar o gene que expressa a TSST-1 em Staphylococcus spp. isolados de leite de vacas.

\section{Material e métodos}

Foi avaliado um total de 264 estirpes de Staphylococcus spp. isolado de leite de vacas com mastite $(n=168)$ e de leite cru refrigerado $(n=96)$. Estudos morfológicos, bioquímicos e moleculares prévios demonstraram que desse total, 221 eram Staphylococcus aureus, 33 Staphylococcus coagulase negativo (SCN) e 10 Staphylococcus coagulase positivo (SCP). A identificação morfológica e bioquímica dos isolados consistiu em análises de coloração de Gram, produção de catalase, acetoína e produção de coagulase em plasma de coelho. Foram classificados como $S$. aureus os micro-organismos que apresentaram forma cocos, reação positiva na coloração de Gram, reação positiva no teste de catalase, acetoína e coagualse. Estirpes com essas mesmas características, porém negativas para a produção de acetoína, foram caracterizadas como Staphylococcus coagulase positiva e aquelas que não apresentaram produção de coagulase e nem de acetoína classificadas como Staphylococcus coagulase negativa (Roberson et al., 1998; Marshall, 1992). A identificação molecular dos isolados ocorreu pela detecção do gene femA. Para tal detecção foram utilizados oligonucleotídeos que amplificam um fragmento do gene femA, de 125pares de bases (pb), específico de S. Aureus.

Para a pesquisa do tst-1 utilizou-se a técnica de Reação em Cadeia da Polimerase (PCR). Inicialmente, realizou-se a extração do DNA bacteriano segundo Rosec e Gigaud (2002) com modificações. O DNA foi extraído a partir de lise térmica. Em seguida, o DNA extraído foi quantificado em espectrofotômetro (GeneQuant Pro, Amersham Biosciences) e as concentrações ajustadas em $100 \mathrm{ng} / \mu \mathrm{L}$ para a PCR, empregando-se o comprimento de onda de 260 e $280 \mathrm{~nm}$. Para as amplificações utilizaram-se oligonucleotídeos iniciadores que amplificam um fragmento do gene tst- 1 de 250 pares de bases (pb) e descritos anteriormente por Schmitz et al (1998), sendo as mesmas conduzidas em termociclador GeneAmpÒ PCR System 9700 (Applied Biosystems) programado para um ciclo inicial a $94^{\circ} \mathrm{C}$ por 3 minutos, seguido de 35 ciclos (desnaturação a $94^{\circ} \mathrm{C} / 30$ seg. - anelamento a $57^{\circ} \mathrm{C} / 30 \mathrm{seg}$. extensão a $72^{\circ} \mathrm{C} / 30$ seg.), com o término da reação a $72^{\circ} \mathrm{C} / 10$ minutos. Como controle positivo para PCR foi utilizado estirpe padrão com genótipo conhecido (S. aureus ATCC 51651) e como controle negativo água bidestilada. Os amplicons foram analisados em eletroforese em gel de agarose (1,8\%), preparado em solução tampão 1,0x TBE e corado com brometo de etídio. Os géis foram em seguida fotografados sob luz ultravioleta em fotodocumentador Eagle Eye Stratagene Co. Os marcadores de peso molecular utilizados foram 100 a $2000 \mathrm{pb}$.

\section{Resultados e discussão}

Dos isolados analisados para a detecção do tst-1, verificou-se que $2,65 \%$ (7/264) amplificaram o gene. Todos os isolados pertenciam a amostras de leite cru refrigerado coletadas no estado do Rio de Janeiro e foram detectados apenas em Staphylococcus aureus (Figura 1).

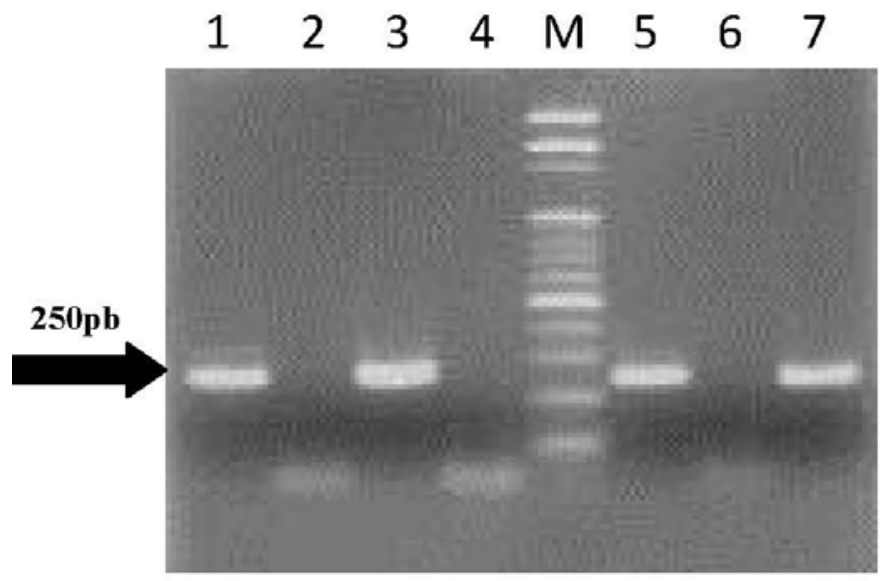

Figura 1: Eletroforese do fragmento do gene tsti-1 (250 pb) de Staphylococcus aureus isolados de leite cru refrigerado, em gel de agarose $2 \%(M=$ marcador molecular; 1, 2, 3, 6 e 7= amostras testadas; $4=$ controle negativo; $5=$ controle positivo)

A baixa ocorrência de genes codificadores da TSST-1 em leite vem sendo relatada também por diferentes autores: Karahan et al. (2009) encontraram presença do gene em 3,3\% S. aureus isolados de leite de vacas com mastite; Nemati et al. (2008) ao analisarem SCN isolados de mastite bovina não detectaram tst-1 em nenhum isolado, assim como Peles et al. (2007), quando pesquisaram o gene em $S$. aureus isolados de mastite e Sidhu et al. (2006) que encontraram tst-1 em apenas $0,01 \%$ dos isolados. Por outro lado, resultados diferentes foram obtidos por Stephan et al. (2001), os quais verificaram que $64,7 \%$ dos $S$. aureus isolados de mastite bovina produziam TSST-1, por Takeuchi et al. (1998), os quais quantificaram TSST-1 em 75,4\% das amostras de $S$. aureus isoladas de leite cru refrigerado e por Farahmand-Azar et al. (2013), Srinivasan et al. (2006), e Zschock et al. (2000) que embora tenham encontrado resultados semelhantes entre si (15,5\%, 20,2\%, 25,6\%, respectivamente), também difere dos encontrados neste estudo.

A baixa porcentagem de isolados contendo tst-1 encontrada neste estudo, associada ao fato de esta toxina não estar envolvida em casos de intoxicações alimentares, não deixa de ser preocupante. Isto porque alguns estudos têm relatado a associação da presença de tst-1 com a presença de genes das enterotoxinas estafilocócicas, as quais estão envolvidas em casos de surtos alimentares em todo o mundo (Zschock et al., 2000; Salasia et al., 2004; Stamford et al., 2006; Morandi et al., 2007; Schelin et al., 2011). Além disso, já foi reconhecido há muitos anos que TSST-1 de Staphylococcus é a principal causa da síndrome do choque tóxico em humanos. Por fim, as 
estipes bacterianas que apresentaram tst-1 podem ser utilizadas para fins de levantamentos epidemiológicos e para um controle dos rebanhos brasileiros, uma vez que alguns trabalhos têm demonstrado que esse gene é carreado por elementos genéticos móveis, implicando uma possível transferência horizontal para outras bactérias (Chiang et al., 2008; Schelin et al., 2011).

$O$ fato de apenas o leite cru refrigerado ter apresentado tst-1 sugere que, para os isolados de mastite bovina avaliados, a presença desse gene não estava envolvido com a patogênese

\section{Referências}

BERGDOLL, M S. 1997. Toxic shock syndrome. Rev. J. Venom. Anim.Toxins, v. 1, p. 6-21.

BUONPANE, R.A.; MOZA, B.; SUNDBERG, E.J.; KRANZ, D.M. Characterization of $T$ cell receptors engineered for high affinity against toxic shock syndrome toxin-1. Journal Molecular Biology, v. 353, p. 308-321, 2005.

CHIANG,Y.C.; LIAO, W.W.; FAN, C.M.; PAI, W.Y.; CHIOU, C.S.; TSEN, H.Y. PCR detection of Staphylococcal enterotoxins (SEs) $\mathrm{N}, \mathrm{O}, \mathrm{P}, \mathrm{Q}, \mathrm{R}, \mathrm{U}$, and survey of SE types in Staphylococcus aureus isolates from food-poisoning cases in Taiwan. International Journal of Food Microbiology, v. 121, p. 66-73, 2008.

CUNHA, M.R.L.S.; CALSOLARI, R.A.O.; ARAUJO JR, J.P. Detection of enterotoxinand toxic shock syndrome toxin 1 gene in Staphylococcus with emphasis on coagulase negative Staphylococcus. Microbiology and Immunology, v. 51, n. 4, p. 381-390, 2007.

DEURENBERG, R.H.; NIEUWENHUIS, R.F.; DRIESSES, C.; LONDON, N.; STASSEN, F.R.; van TIEL, F.H.; STOBBERINGH, E.E.; VINK, C. The prevalence of the Staphylococcus aureus tst gene among community and hospital acquired strains and isolates from Wegener's Granulomatosis patients. FEMS Microbiology Letters, v. 245, p.185-189, 2005.

DINGES, M.M.; ORWIN, P.M.; SCHLIEVERT, P.M. Exotoxins of Staphylococcus aureus. Clinical Microbiology Reviews, v. 13, p. 16-34, 2000.

FARAHMAND-AZAR, S.; AHMADI, M.; DASTMALCHI SAEI, H., ANASSORI, E. Identification of Toxic Shock Syndrome Toxin-1 (TSST-1) gene in Staphylococcus aureus isolated from bovine mastitis milk. Archives of Razi Institute, v. 68, n. 1, p. 17-22, 2013.

FERNANDEZ, M.M.; MARZI, M.C.; BERGUER, P.; BURZYN, D.; LANGLEY, R. J.; PIAZZON, I.; MARIUZZA, R.A.; MALCHIODI, E.L. Binding of natural variants of staphylococcal superantigens SEG and SEI to TCR and MHC classe II molecule. Molecular Immunology, v. 43, p. 927-938, 2006.

GÜNAYDIN, B.; ASLANTAŞ, O.; DEMIR, C. Detection of superantigenic toxin genes in Staphylococcus aureus strains from subclinical bovine mastites. Tropical Animal Health and Production, v. 43, p. 1633-1637, 2011.

HALE, M.L.; SWIETNICKI, W. Model systems to study a superantigen-induced disease: Toxic shock syndrome. Infections diseases, v. 3, n. 1, 121-126 p., 2006.

JONES, T.O.; WIENEKE, A.A. Staphylococcal toxic shock syndrome. The Veterinary. Record., v. 119, p. 435-436, 1986.

KAEMPFER, R. Peptide antagonists of superantigen toxins. Molecular Diversity, v. 8, p. 113-120, 2004. da mastite, embora não se possa descartar a presença desse gene e consequentemente sua interferência na gravidade e persistência da doença em outros rebanhos.

\section{Conclusões}

Os dados encontrados sugerem a necessidade de mais estudos envolvendo um maior número de rebanhos e um maior número de isolados da região para avaliar o risco para a saúde pública do consumo do leite contendo tst-1.

KARAHAN, M.; AÇIK, M.N.; ÇETINKAYA, B. Investigation of Toxin Genes by Polymerase Chain Reaction in Staphylococcus aureus Strains Isolated from Bovine Mastitis in Turkey. Foodborne pathogens and disease, v. 6, n. 8, p. 1029-1035, 2009.

LOVSETH, A.; LONCAREVIC, S.; BERDAL, K.G. Modified multiplex PCR method for detection of pyrogenic exotoxin genes in staphylococcal isolates. Journal of Clinical Microbiology, v. 42, p. 3869-3872, 2004.

MORANDI, S.; BRASCA, M.; LODI, R.; CREMONESI, P.; CASTIGLIONI, B. Detection of classical enterotoxins and identification of enterotoxin genes in Staphylococcus aureus from milk and dairy products. Veterinary Microbiology, v. 124, p. $66-72$, 2007.

NEMATI, M.; HERMANS, K.; VANCRAEYNEST, D.; DE VLIEGHER, S.; SAMPIMON, O.C.; BAELE, M.; DE GRAEF, E.M.; PASMANS, F.; HAESEBROUCK, F. Screening of bovine coagulase-negative staphylococci from milk for superantigenencoding genes. The Veterinary Record, v. 163, p. 740-743, 2008.

PELES, F.; WAGNER, M.; VARGA, L.; HEIN, I.; RIECK, P.; GUTSER, K.; KERESZTÚRI, P.; KARDOS, G., TURCSÁNYI, I.; BÉRI, B.; SZABÓ, A. Characterization of Staphylococcus aureus strains isolated from bovine milk in Hungary. International Journal of Food Microbiology, v. 118, p. 186-193, 2007.

ROSEC, J.P.; GUIGAUD, O. Staphylococcal enterotoxin genes of classical and new types detected by PCR in France. International Journal of Food Microbiology, v.77, p. 61-70, 2002.

SALASIA, S.I.O.; KHUSNAN, Z.; LÄMMLER, C.; ZSCHÖCK, $M$. Comparative studies on pheno- and genotypic properties of Staphylococcus aureus isolated from bovine subclinical mastitis in central Java in Indonesia and Hesse in Germany. Journal of Veterinary Science, v. 5, n. 2, p. 103-109, 2004.

SCHELIN, J.; WALLIN-CARLQUIST, N.; COHN, M.T.; LINDQVIST, R.; BARKER, G.C.; RADSTROM, P. The formation of Staphylococcus aureus enterotoxin in food Environments and advances in risk assessment. Virulence,,v. 2, n. 6, p. 580-592, 2011.

SCHMITZ, F.J.; STEIERT, M.; HOFMANN, B.; VERHOEF, J.; HADDING, U.; HEINZ, H.P.; KÖHRER, K. Development of a multiplex-PCR for direct detection of the genes for enterotoxin $\mathrm{B}$ and $\mathrm{C}$, and toxic shock syndrome toxin-1 in Staphylococcus aureus isolates. Journal of Medical Microbiology, v. 47, p. 335340, 1998.

SIDHU, M.; GURJAR, A.; HEGDE, N.; LOVE, B.; JAYARAO, B. Detection of enterotoxigenic of strains of Staphylococcus aureus using multiplex PCR. NMC Annual Meeting Proceedings, 2006.

SRINIVASAN, V. SAWART, A.A.; GILLERPIE, B.E.; HEADRICK, S.I.; CEASARIS, L.; OLIVER, S.P. Characterization of enterotoxin and toxic shock syndrome genes in Staphylococcus aureus isolated from milk of cows with mastitis. NMC Annual Meeting Proceedings, 2006. 
STAMFORD, T.L.M.; SILVA, C.G.M.; MOTA, R.P.; NETO, A.C. Enterotoxigenicidade de Staphylococcus spp. isolados de leite in natura. Ciência e Tecnologia de Alimentos, v. 26, n. 1, p. 41-45, 2006.

STEPHAN, R.; ANNEMULLER, C.; HASSAN, A.A.; LAMMLERB, C.H. Characterization of enterotoxigenic Staphylococcus aureus strains isolated from bovine mastitis in north-east Switzerland. Veterinary Microbiology, v. 78, p. 373-382, 2001.

STILES, B.G.; KRAKAUER, T. Staphylococcal enterotoxins: a purging experience in Review, Part 1. Clinical Microbiology Newsletter, v. 27, n. 23, p. 179-186, 2005.

SKOV, L.; BAADSGAARD, O. The potential role of Staphylococcus aureus superantigens in atopic eczema. Journal of the European Academy of Dermatology and Venereology, v. 7 (Suppl. 1), p. S8-S11, 1996.

TAKEUCHI, S., ISHIGURO, K., IKEGAMI, M. et al. Production of toxic shock syndrome toxin by Staphylococcus aureus isolated from mastitic cow's milk and farm bulk milk. Veterinary Microbiology, v. 59, p. 251-258, 1998.
TSEN, H.Y.; YU, G.K.; WANG, K.C.; WANG, S.J.; CHANG, M.Y.; LIN, L.Y. Comparison of the enterotoxigenic types, toxic shock syndrome toxin 1 (TST-1) strains and antibiotic susceptibilities for enterotoxigenic Staphylococcus aureus strains isolated from food and clinical samples. Food Microbiology, v. 15, p. 33-41, 1998.

ZSCHOK, M.; BOTZLER, D.; BLOCHER, S.; SOMMERHAUSER, J.; HAMANN, H. P. Detection of genes for enterotoxins (ent) and toxic shock syndrome toxin-1 (tst) in mammary isolates of Staphylococcus aureus by polymerase-chain-reaction. International Dairy Journal, v.10, p. 569-574, 2000.

ZSCHOCK, M.; KLOPPERT, B.; WOLTER, W.; HAMANN, H.P.; LAMMLER, C. Pattern of enterotoxin genes seg, seh, sei and sej positive Staphylococcus aureus isolated from bovine mastitis. Veterinary Microbiology, v. 108, p. 243-249, 2005.

WANG, S.C.; WU, C.M.; XIA, S.C.; HUA, Y.; XIA, L.N.; SHEN, J.Z. Distribution of superantigenic toxin genes in Staphylococcus aureus isolates from milk samples of bovine subclinical mastitis cases in two major diary production regions of China. Veterinary Microbiology, v. 137, p. 276-281, 2009. 